\title{
A pesca e o conhecimento ecológico local dos pescadores de acará-disco (Symphysodon aequifasciatus, Pellegrin 1904: Cichlidae) na Reserva de Desenvolvimento Sustentável Piagaçu-Purus, baixo rio Purus, Brasil
}

Fishery and local ecological knowledge of the discus (Symphysodon aequifasciatus, Pellegrin 1904: Cichlidae) fishermen in the Reserva de Desenvolvimento Sustentável Piagaçu-Purus, lower Purus River, Brazil

\author{
Felipe Rossonil, Efrem Ferreira", Jansen Zuanon" \\ Instituto Piagaçu. Manaus, Amazonas, Brasil \\ "Instituto Nacional de Pesquisas da Amazônia. Manaus, Amazonas, Brasil
}

\begin{abstract}
Resumo: O acará-disco (Symphysodon aequifasciatus, Pellegrin 1904), peixe endêmico da bacia amazônica, é uma das espécies ornamentais mais conhecidas do mundo. Apesar disso, informações sobre a explotação desse animal em vida livre são quase inexistentes na literatura científica. Nesse artigo, a pesca de pequena escala do acará-disco na Reserva de Desenvolvimento Sustentável Piagaçu-Purus (RDS-PP), baixo rio Purus, Amazonas, é caracterizada com base em entrevistas estruturadas e abertas com pescadores e habitantes, bem como em observações de campo. A pesca do acará-disco é sazonal, ocorrendo durante o período de seca. É realizada por pescadores locais, utilizando atratores de pesca e uma técnica de detecção e estimativa de abundância por mergulho em apneia. $\bigcirc$ armazenamento local é feito em tanques de madeira e os peixes são transportados em recipientes plásticos para distribuição nos mercados regionais por meio de barcos dos próprios pescadores, barcos de linha ou jangadas. Os peixes são vendidos para empresas exportadoras especializadas de Manaus. Neste estudo, descrevemos o conhecimento ecológico local dos pescadores de acará-disco na RDS-PP e discutimos sua importância para a gestão da pesca nessa unidade de conservação.
\end{abstract}

Palavras-chave: Pesca. Peixe ornamental. Manejo de recursos naturais. Atrator de pesca. Amazônia.

\begin{abstract}
The discus fish (Symphysodon aequifasciatus, Pellegrin 1904), an endemic cichlid from the Amazon basin, is one of the most popular ornamental fish species in the world. However, there is little information available in the scientific literature on the exploitation of this species in its natural habitat. In this article we describe the small-scale discus fisheries activity in the Reserva de Desenvolvimento Sustentável Piagaçu-Purus (RDS-PP), lower Purus River, Brazil, based on field observations, structured and open-ended interviews with fishermen and local inhabitants. Discus fishery is seasonal, occurring mainly in the dry season. Local fishermen use fish attractors to catch the species and underwater hearing methods to estimate its presence and abundance. Discus fishes are locally kept in wooden storage tanks and carried in plastic containers for distribution in regional markets by means of fishing boats, commercial boat lines or rafts. Discuses are sold in Manaus, State of Amazonas, to export companies specialized in ornamental fish trade. We describe the local ecological knowledge on the discus among fishermen living within the RDS-PP and discuss its importance for ornamental fishery management in that protected area.
\end{abstract}

Keywords: Fishery. Ornamental fish. Natural resources management. Artificial fishing attractor. Amazonia.

ROSSONI, Felipe; FERREIRA, Efrem; ZUANON, Jansen. A pesca e o conhecimento ecológico local dos pescadores de acará-disco (Symphysodon aequifasciatus, Pellegrin 1904: Cichlidae) na Reserva de Desenvolvimento Sustentável Piagaçu-Purus, baixo rio Purus, Brasil. Boletim do Museu Paraense Emílio Goeldi. Ciências Humanas, v. 9, n. 1, p. 109-128, jan.-abr. 2014.

Autor para correspondência: Felipe Rossoni. Instituto Piagaçu - Programa de Conservação e Manejo de Recursos Pesqueiros. Rua U/Z, n. 8. Quadra Z. Conjunto Morada do Sol - Aleixo. Manaus, AM, Brasil. CEP 69060-095 (feliperossoni@gmail.com).

Recebido em 07/05/2012

Aprovado em 13/12/2013

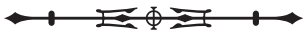




\section{INTRODUÇÃO}

Com estimativa de mais de 2.500 espécies de peixes, a ictiofauna amazônica é considerada a mais diversa do planeta em relação a ambientes de água doce (Reis et al., 2003). Historicamente, os rios desempenharam um papel fundamental na ocupação e colonização da Amazônia; intimamente relacionada a esses ambientes está a exploração dos recursos pesqueiros, com destacado papel socioeconômico, quer como produtora de alimento, quer como geradora de trabalho, renda e lazer para milhares de pessoas (Santos et al., 2006). Entre as atividades pesqueiras, ocorre a exploração de peixes para fins de aquariofilia, principalmente de espécies de pequeno porte, com formas exóticas e colorido exuberante.

A pesca de peixes ornamentais no estado do Amazonas teve início na década de 1930. A partir da década de 1950, começou a haver um aumento na demanda, por parte dos mercados dos Estados Unidos, Europa e Ásia (Denis, 1985 apud Leite e Zuanon, 1991; Crampton, 1999a), chegando ao auge nas décadas de 1970 e 1980 até meados da década de 1990. O Brasil foi o maior exportador de peixes ornamentais de água doce do mundo, sendo a bacia amazônica a grande fonte deste recurso (McGrath, 1990; Crampton, 1999a). Atualmente, a Colômbia exporta por ano a maior quantidade de peixes ornamentais dulcícolas da América do Sul, embora países como Peru, Brasil e Venezuela também participem das exportações (Prang, 2007).

Anjoset al. (2009) mencionam que, aproximadamente, 100 milhões de peixes ornamentais foram exportados do Amazonas entre os anos de 2002 e 2005, correspondendo a US\$ 9,6 milhões para o mercado externo e $R \$ 1,5$ milhão para o mercado interno. Esse volume passou de uma taxa média anual de captura de 17 milhões de peixes, em 2002, para 36,2 milhões, em 2005, com um crescimento de $28 \%$. Nesse contexto, o rio Negro foi responsável por fornecer mais de $90 \%$ dos exemplares de peixes ornamentais no Amazonas. Segundo alguns autores (Prang, 2001a, 2001b; Chao, 1993; Chao et al., 2001), a pesca de peixes ornamentais já empregou mais de dez mil pessoas no Amazonas, tendo o município de Barcelos como centro da atividade, onde mais de $60 \%$ da renda municipal foi oriunda da pesca de peixes ornamentais.

Além do rio Negro, outras bacias hidrográficas, como as dos rios Juruá e Purus, contribuem para a atividade, principalmente para espécies de 'corredeira' ou 'corredora' (Corydoras spp., Callichthyidae) e 'limpavidro' (Otocinclus spp., Loricariidae). O rio Purus contribui, aproximadamente, com 1,5\% do volume exportado do Amazonas, segundo valores declarados por atacadistas autorizados (Anjos et al., 2009).

Apesar da dimensão econômica, esta atividade ainda mostra deficiências, sendo muito lucrativa somente para poucos elos envolvidos na cadeia produtiva. Historicamente, as altas taxas de mortalidade no decorrer do processo, a falta de conhecimento sobre as espécies utilizadas, bem como a ineficiência do empreendimento, resultaram em danos ambientais e econômicos para o país (Leite e Zuanon, 1991). Lima (2004) aponta a carência de dados sobre o mercado, a vulnerabilidade ambiental (referente aos impactos nos ambientes e nos estoques) e a falta de políticas públicas de fomento como fatores que aumentam as dificuldades para a normatização da atividade no país.

No Brasil, são permitidas a captura, o transporte e a comercialização de exemplares vivos de 725 espécies (ou grupo de espécies) de peixes nativos de água doce, além de licenças especiais, por meio de cotas, para seis espécies de raias (Potamotrygonidae) dulcícolas (IBAMA, 2008; Brasil, 2012). Entre estas, uma das mais conhecidas mundialmente no mercado de ornamentais é o acarádisco (Symphysodon spp., Cichlidae) (Leite e Zuanon, 1991; Chao, 1993, 2001).

A pesca de acará-disco é feita de forma completamente artesanal e acontece em lagos, por meio de dois apetrechos: rapiché (puçá) e rede-de-cerco. O rapiché é adotado à noite, quando o pescador utiliza uma lanterna para focar (localizar iluminando) os animais e capturá-los individualmente (Prang, 2001a, 2007). A rede-de-cerco é usada em pescarias diurnas para capturar um maior 
número de indivíduos, que se encontram agrupados entre ramos e troncos submersos.

Na Reserva de Desenvolvimento Sustentável ${ }^{1}$ Piagaçu-Purus (RDS-PP), baixo rio Purus, Amazonas, a pesca do acará-disco é realizada de forma diferenciada, por meio do preparo de atratores de pesca, ou microhabitats artificiais, localmente chamados de 'galhadas', que são colonizados por várias espécies de peixes, incluindo os acarás-discos. Entretanto, são quase inexistentes trabalhos na literatura científica que referenciem esse tipo de metodologia de pesca para a Amazônia. Essa carência de informação impede uma análise mais acurada das características, das peculiaridades, da eficiência e do potencial desse método como estratégias para uma exploração racional desse recurso pesqueiro na região.

As atividades de exploração do acará-disco desenvolvidas pelos moradores da região carecem de orientação técnica. Observa-se também ausência de uma dinamização para cadeias produtivas sustentáveis e de certificação socioambiental. Dessa forma, são necessárias pesquisas que abordem a pesca ornamental do ponto de vista do manejo de pequena escala, buscando integrar o conhecimento local dos pescadores com informações técnicas a respeito das espécies e do potencial de comercialização.

Segundo Berkes et al. (2006), as ciências pesqueiras não têm servido às necessidades da gestão da pesca no hemisfério sul. Os autores apontam que, além do foco geográfico centrado nos países do hemisfério norte, essa disciplina concentra-se em aspectos biológicos e, até certo ponto, econômicos. Porém, existem diversas novas abordagens que enfatizam processos de decisão interdisciplinares e participativos para a gestão pesqueira, incluindo a incorporação do conhecimento local de pescadores. Segundo os autores, avaliações pesqueiras locais podem se basear, preliminarmente, no conhecimento ecológico local (LEK - sigla em inglês do termo Local Ecological Knowledge), incluindo aspectos da ecologia, do comportamento e de outras informações decorrentes da experiência local acumulada.

Somando-se a isso, Ruddle (2000) menciona como essencial o entendimento das bases sociais do conhecimento local e das relações cognitivas entre esse conhecimento acerca dos peixes e suas aplicações nas atividades pesqueiras.

$O$ presente trabalho apresenta uma abordagem holística da pesca do acará-disco na RDS-PP, com base em informações sobre o conhecimento ecológico local dos pescadores da reserva. Partindo desse princípio, as informações levantadas são discutidas no contexto do LEK, que, segundo Silvano (2004), pode fornecer subsídios importantíssimos para a gestão da pesca, além de contribuir para a redução do ceticismo acadêmico sobre o conhecimento etnobiológico. O conhecimento local poderá ser utilizado no manejo pesqueiro, fornecendo diretrizes para a pesquisa biológica e contribuindo para o desenvolvimento de estratégias de manejo compartilhado (Begossi et al., 2006).

\section{MATERIAL E MÉTODOS}

A caracterização da pesca do acará-disco na RDS-PP é apresentada com base em informações coletadas a partir de entrevistas e observações diretas em campo. Inicialmente, foi realizado um levantamento das áreas de pesca e dos pescadores de peixes ornamentais que atuam na RDS-PP, segundo informações de pesquisadores e relatórios internos do Instituto Piagaçu (IPI) (dados não publicados), bem como visitas de reconhecimento. Como o número de pescadores de acará-disco que se envolvem (ou já se envolveram) na atividade não era expressivo, e eles não estavam concentrados em uma determinada comunidade, optamos por uma amostragem do tipo 'bola

\footnotetext{
No Brasil, segundo o Sistema Nacional de Unidades de Conservação (Brasil, 2000), Reserva de Desenvolvimento Sustentável (RDS) é uma unidade de conservação, do grupo uso sustentável, descrita como uma área natural protegida, onde vivem populações tradicionais que se baseiam em sistemas sustentáveis de exploração dos recursos naturais, desempenhando papel fundamental na proteção da natureza e na manutenção da diversidade biológica.
}

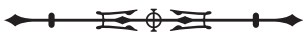


de neve' (snow-ball, conforme Bailey, 1987). Segundo esse autor, as pessoas que possuem reputação sobre a atividade de interesse são indicadas pelos comunitários locais e, ao final de cada entrevista, pede-se a recomendação de mais uma pessoa que conheça o assunto.

Foram realizadas entrevistas abertas e aplicados questionários estruturados com 20 conhecedores do assunto, ou que possuíam informações relevantes sobre o histórico da pesca nos diferentes locais da RDS-PP. Os questionários continham perguntas relativas ao histórico da atividade, aos locais de pesca, às formas de captura e armazenamento, às quantidades capturadas, à comercialização e aos problemas enfrentados. Quando possível, foram realizadas observações diretas nos locais de pesca. As entrevistas e observações foram realizadas nos setores Jari (lago Jari), Ayapuá (cabeceira e paraná do lago Ayapuá) e Uauaçu (incluindo o paraná e o lago Uauaçu) (Figura 1), durante o período de 2006 e 2007, com pelo menos uma viagem a campo em cada local. Algumas entrevistas foram gravadas, com o consentimento do entrevistado.

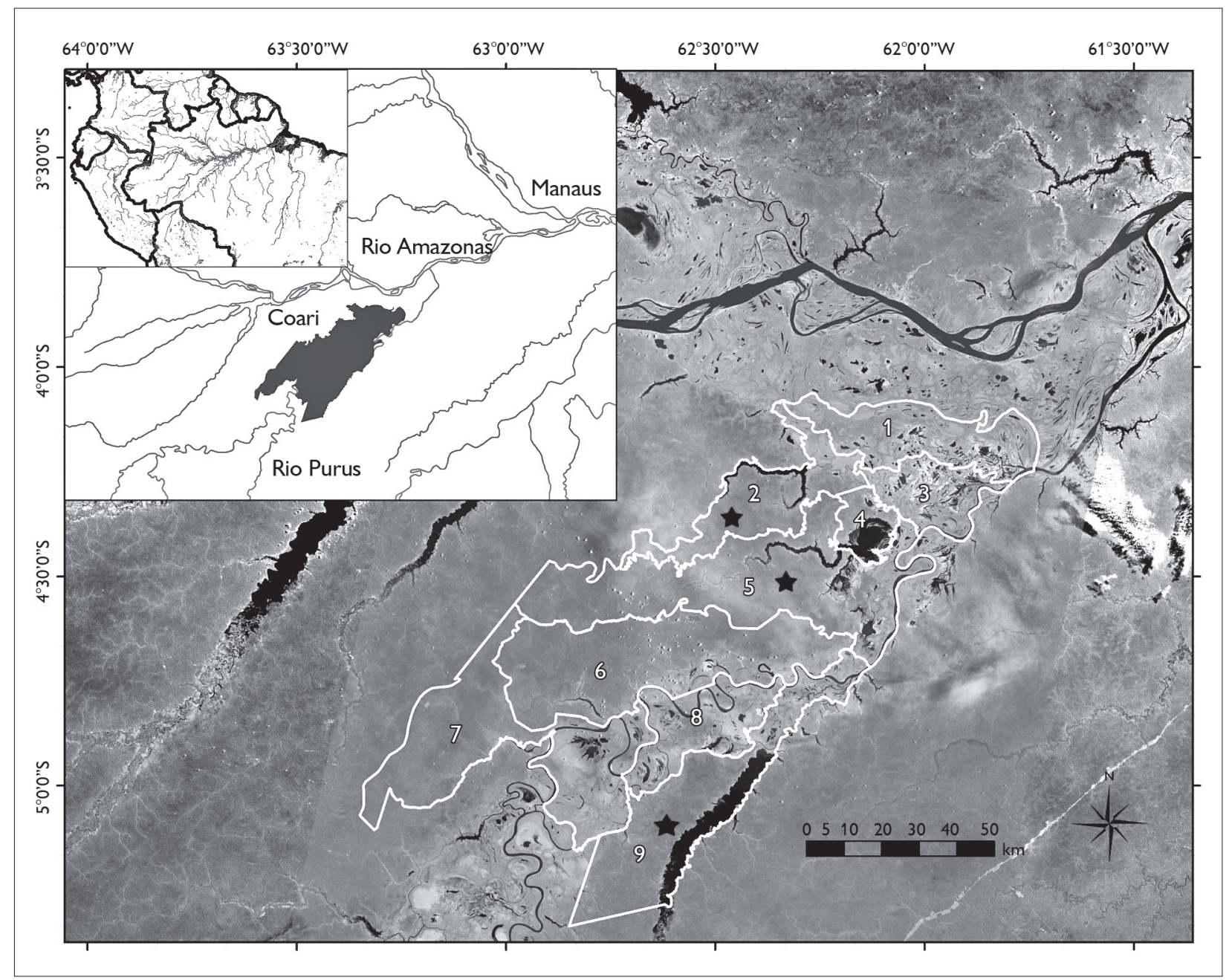

Figura 1. Mapa com localização geográfica da região do baixo rio Purus, representando a Reserva Biológica de Abufari (REBIO), as Terras Indígenas (TI) e a Reserva de Desenvolvimento Sustentável Piagaçu-Purus (subdividida em setores): 1 - setor Caua-Cuiuanã; 2 - setor Uauaçu; 3 - setor Itapuru; 4 - TI Mura do Lago Ayapuá; 5 - setor Ayapuá; 6 - TI Apurinã Itixi Mitari; 7 - setor Supiá-Três Bocas; 8 - setor Paraná do Jari; 9 - setor Jari-Arumã. Legenda: $\star=$ setores onde foi identificada pesca de acará-disco.

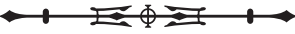


Foram investigadas e descritas as estratégias praticadas pelos pescadores, atravessadores e/ou compradores, ao longo da cadeia de produção e comercialização no interior da RDS-PP. Realizou-se um levantamento e a subsequente descrição dos apetrechos e das técnicas de pesca, das metodologias, dos locais, da sazonalidade, das táticas e dos materiais utilizados na captura, no armazenamento e transporte dos peixes. Características dos processos de póscaptura também foram descritas, como locais para estocagem, tipo e tamanho de viveiros, material de construção, locais para a instalação, alimentação e densidade de peixes.

\section{RESULTADOS}

\section{SAZONALIDADE E AMBIENTES DE PESCA}

A pesca do acará-disco na RDS-PP é realizada na época que compreende o final da vazante, a seca e o início da enchente, geralmente coincidindo com o período do final de setembro ao início de novembro. Com a retração dos ambientes aquáticos na estiagem amazônica, há um grande aumento na concentração de peixes nos ambientes remanescentes. $\bigcirc$ acará-disco é encontrado em locais regionalmente chamados de 'galhadas' ou 'pausadas'. Esses hábitats são amontoados de troncos/ramos de vegetação marginal, resultantes da queda de árvores e que permanecem total ou parcialmente submersos junto às margens, no período em que não há mais vegetação marginal naturalmente submersa (Figura 2A). A captura do acará-disco ocorre exclusivamente nessa época, quando são encontrados grandes agrupamentos de peixes. Passado esse período, a captura torna-se difícil e, consequentemente, o interesse pela atividade diminui.

Os maiores agrupamentos de acarás-discos são encontrados em galhadas/pausadas ao longo das margens dos lagos, principalmente nos 'braços de lagos' e 'bocas de igarapés', mas também podem estar distribuídos em paranás (conexões entre lagos ou entre rio e lagos).

Foi consenso entre os entrevistados que o acarádisco geralmente habita locais de média profundidade (de 1,5 a 2,5 m), com baixa ou nenhuma correnteza. A partir do início da enchente, os acarás-discos deslocam-se para as margens dos lagos, na medida em que o nível da água sobe, e ocupam as áreas colonizadas por herbáceas aquáticas para, posteriormente, ocupar a floresta alagada. Porém, segundo alguns entrevistados, os peixes deslocamse em direção à cabeceira desses 'braços de lagos' e, em seguida, invadem a floresta alagada.

\section{A PESCARIA DE ACARÁS-DISCOS NA RDS-PP}

Até o final da década de 1990, a pesca na RDS-PP era realizada explorando-se as 'galhadas' naturais em que eram encontradas as maiores concentrações de peixes. Para a captura dos acarás-discos nesses locais, utilizavase uma rede de cerco ou arrasto ('redinha') de malha fina (em torno de 8 a 12 mm entre nós opostos). Em alguns casos, essa rede (bem como outros materiais) era fornecida aos pescadores por empréstimo ou aluguel pelas empresas e/ou atravessadores. A rede era disposta de modo a cercar completamente a 'galhada', sendo a margem utilizada como apoio para as pontas da rede (Figura 2B). Após o cerco, todos os ramos da vegetação eram cortados e removidos, resultando em um ambiente sem obstáculos para o recolhimento da rede, até o ponto em que os peixes capturados ficassem mais concentrados e expostos. Frequentemente, havia no cerco um grande número de outros peixes, além dos acarás-discos.

Essa descrição geral da pesca foi relatada uniformemente em todas as entrevistas, não havendo discrepância entre as informações. Relatou-se também uma técnica utilizada para avaliar se há acarás-discos em uma 'galhada'/'pausada'. A técnica consiste em ouvir e/ou sentir as vibrações dos peixes quando estes se movimentam entre os ramos da vegetação. Segundo os pescadores, eles ficam abrigados muito próximos ou encostados nos ramos. Quando há uma pequena perturbação, como uma batida com o remo ou um pequeno movimento dos galhos, os peixes deslocam-se no ambiente. Essa movimentação em massa pode ser 


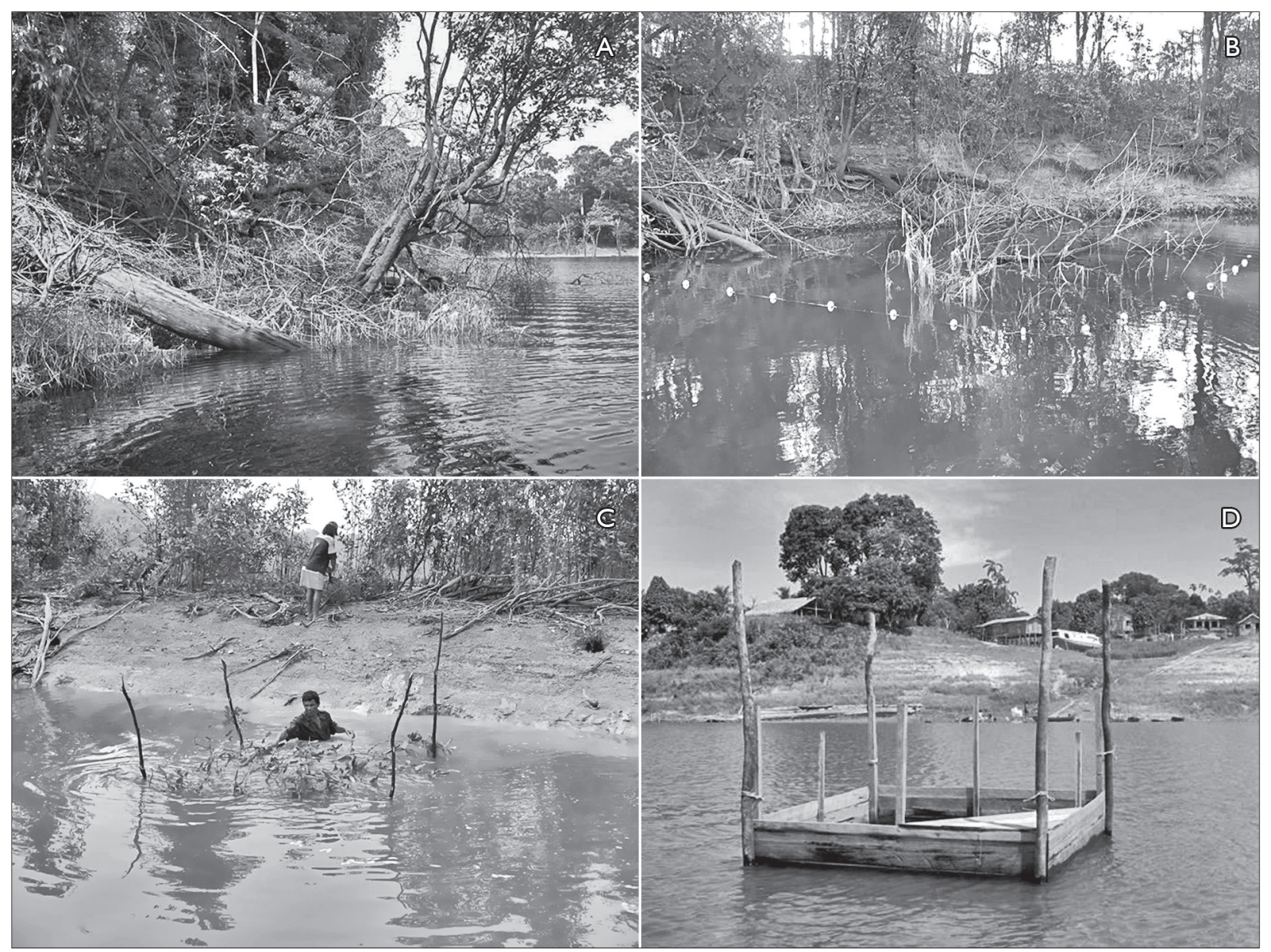

Figura 2. (A) Ambiente de troncos e ramos de vegetação ('pausada'), parcialmente submersos na margem do lago Ayapuá; (B) 'pausada' cercada com rede, para captura de acarás-discos; (C) atrator de pesca ('galhada') sendo montado com a utilização de ramos da vegetação marginal; (D) tanque ('curral') utilizado para o armazenamento dos acarás-discos capturados. Fotos: Felipe Rossoni.

percebida pela transferência da vibração dos ramos ao cabo do remo que o pescador está segurando.

Também ocorrem situações em que pescadores mergulham para detectar a presença de acará-disco no ambiente. Quando isso é feito, o pescador pode sentir aquela vibração pelo tato - utilizando-se das mãos, segurando os ramos - e 'ouvindo' a movimentação dos peixes.

Para alguns, o mergulho é a forma mais eficiente de detectar a presença e quantificar a abundância de acarás-discos no ambiente; quando há um pequeno número de peixes, o uso do remo pode não ser eficiente. Questionados sobre a aprendizagem dessa técnica, os pescadores relataram ter aprendido com pessoas mais velhas e experientes. Além disso, apontam o dia-a-dia e o acúmulo de experiência como a melhor forma de aprendizado:

Aprendi [a ouvir o acará-disco] pescando com os outros. É mesmo que você tá numa aula. Aprendi aqui com meu cunhado; já faz mais de 30 anos que pesco. Desde moleque (...) com 15 anos já pescava tudo que é pescaria. (...) $\bigcirc$ cara que tá no ramo conhece; é mesmo o ramo que você anda fazendo, a pesquisa né: se eu vô entrá, eu não sei nem pra onde entra. Mas daí o cara vai escutando, vai vendo o trabalho e vai tomando posse até o conhecimento do trabalho (S. R., paraná do Uauaçu, 2007).

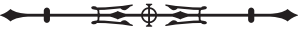


Visando otimizar o esforço de captura, mais recentemente, os pescadores começaram a construir atratores de pesca ('galhadas' artificiais). Essa técnica vem sendo usada há cerca de 15 anos na região da RDS-PP. Esses ambientes são construídos nas margens dos lagos, em entradas de igarapés, na época da seca e no início da enchente, utilizando predominantemente ramos vivos de araçá (Eugenia sp., Myrtaceae), que ocorre nas margens dos lagos. $\bigcirc$ araçá é a melhor opção para a construção dos atratores, pelo fato de possuir ramos pouco flexíveis e folhas pequenas. Também são utilizados ramos de vegetação morta e outras espécies de margem, como o carauaçu (Symmeria paniculata Benth, Polygonaceae). Porém, segundo os pescadores, essa planta é utilizada quando não há araçá no local, pelo fato de os galhos do carauaçu serem muito flexíveis e possuírem folhas grandes; quando dispostos na água, os emaranhados de galhos colapsam, diminuindo os espaços entre os galhos e perdendo a função de disponibilizar refúgio para os peixes. Outras vezes, os pescadores utilizam uma primeira camada do amontoado de galhos já mortos e secos e adicionam uma camada superior de carauaçu ou outra vegetação disponível. $\bigcirc$ objetivo é formar um ambiente mais sombreado, porém, com um bom espaço disponibilizado pelos galhos que ficaram na camada inferior.

Cobrindo uma superfície que varia, em média, de 2 a 4 m²$^{2}$, as 'galhadas' artificiais são mantidas na água durante oito a 20 dias para a colonização pelos peixes. $\bigcirc$ amontoado de galhos é disposto de forma que as bases dos ramos (extremidades que foram cortadas) fiquem voltadas para a margem, em posição horizontal. Cravam-se de quatro a seis varas no fundo, nas extremidades e no centro da 'galhada', com a finalidade de fixá-la melhor, protegendo-a da ação de ventos e enxurradas (Figura 2C). O tempo de disponibilidade do atrator e suas dimensões são fatores que dependem dos locais escolhidos para a construção. Há risco de perdê-lo, caso seja montado em local raso, onde a vazante o deixará rapidamente fora da água, ou por força da correnteza, em caso de grandes chuvas. Geralmente, são construídas 'galhadas' maiores quando há disponibilidade de matéria-prima para a construção.

Após o tempo previsto, as 'galhadas' são 'despescadas': os pescadores cercam o atrator com a rede e identificam se há acarás-discos no local; em caso positivo, retiram os ramos, puxam a rede e os capturam com pequenos puçás. Em caso negativo, deixam a 'galhada' por mais alguns dias. Costumeiramente, quando o local ainda oferece condições, a 'galhada' é remontada para uma segunda pesca.

Sobre essa técnica, também foram unânimes comentários sobre a grande quantidade de peixes que coloniza as 'galhadas'. Segundo um pescador, quando tinha condições (caixa isotérmica e gelo), capturava outros peixes de interesse comercial que estavam presos no cerco, como tucunarés e acarás (Cichlidae) ou, ainda, cuiu-cuiu (Oxydoras niger, Doradidae). Também foram relatados os perigos de realizar a pescaria: há risco de animais perigosos, como raias (Potamotrygonidae), poraquês (Electrophorus electricus, Gymnotidae) e jacarés-tingas (Caiman crocodilus crocodilus), ficarem presos durante o cerco da 'galhada'.

Depois de capturados, os acarás-discos são retirados individualmente da rede e depositados em recipientes plásticos ('caçapas', medindo $64 \times 44 \times 19 \mathrm{~cm}$, com 15 a 20 l de água), variando de três a cinco indivíduos/'caçapa' - dependendo do tamanho dos peixes -, os quais são mantidos em canoas. É costume dos pescadores adicionarem a cada 'caçapa' uma pitada de sal, que, segundo eles, serve para assegurar a melhora rápida de pequenos ferimentos que possam ter ocorrido durante o processo de captura. Ainda foi citado por alguns entrevistados que certas empresas exportadoras e/ou atravessadores fornecem medicamentos para serem utilizados de forma preventiva nas 'caçapas', durante o transporte.

Em geral, os pescadores de acarás-discos utilizam canoas de madeira, impulsionadas por pequenos motores estacionários, adaptados como propulsores, conhecidos localmente como 'rabetas'. Geralmente, uma canoa maior 
é levada para acondicionar as 'caçapas' e outras pequenas são utilizadas para a construção das 'galhadas' e para a realização do cerco com a rede.

\section{O ARMAZENAMENTO E O TRANSPORTE}

Após a captura, os animais são transportados para tanques ou viveiros, denominados 'currais' (Figura 2D), posicionados estrategicamente em distâncias que permitem acesso rápido a partir de várias 'galhadas'. Confeccionados com madeira do local, esses tanques são montados na própria comunidade. Os 'currais' variam em torno de 2 $\mathrm{m}^{3}$, onde os animais vão sendo estocados até o término da temporada de pesca, em locais com condições ambientais semelhantes ao de captura.

É importante que haja circulação de água e ausência de capim, para evitar a ocorrência de hipóxia (pela decomposição da matéria orgânica) e uma profundidade mínima de 1,5 m, o que ajuda a manter uma temperatura adequada, sem grandes variações. A densidade estimada é de 1.000 a 1.500 peixes por 'curral', dependendo das condições do local onde foi instalado.
Geralmente, os peixes são mantidos durante 2,5 a 3 meses nos viveiros, sendo alimentados até o final da temporada de pesca, quando então serão comercializados. Os peixes só são alimentados após a primeira semana, prática útil para a adaptação ao novo ambiente. Nesse período, ocorre a maior mortalidade dos indivíduos capturados, com relatos mais comuns de 20 a 30\%, mas pode ocorrer até mais de $50 \%$ de mortalidade em condições desfavoráveis de armazenamento e transporte. Segundo alguns pescadores, o peixe cozido é o melhor alimento para os acarás-discos, porém, deve-se tomar cuidado quanto à utilização de espécies 'reimosas'.

Ao final da temporada de pesca, a produção segue para as empresas exportadoras em Manaus. Para o transporte, geralmente são utilizadas as mesmas 'caçapas' plásticas usadas na captura. Em muitos casos, esse material é fornecido por empréstimo, ou até mesmo aluguel, pelas empresas e/ou atravessadores. Os peixes podem seguir para Manaus de três formas distintas: barco próprio ou fretado, barco de linha (transporte regular, conhecido como 'recreio') ou jangadas (Tabela 1).

Tabela 1. Formas de transporte da produção do acará-disco (Symphysodon aequifasciatus), na RDS-PP, Amazonas, Brasil.

\begin{tabular}{|c|c|c|}
\hline Forma de transporte & Característica de uso & Comentário \\
\hline Barco próprio ou fretado & $\begin{array}{l}\text { O pescador possui um barco ou aluga uma } \\
\text { embarcação exclusivamente para o transporte dos } \\
\text { peixes, geralmente quando obteve algum tipo de } \\
\text { empréstimo financeiro da empresa exportadora }\end{array}$ & $\begin{array}{l}\text { "Quando a gente pega condições [financiamento] } \\
\text { da firma dá até pra alugá um barco pra levá o peixe" } \\
\text { (M. B., lago Uauaçu, 2006) }\end{array}$ \\
\hline $\begin{array}{l}\text { Barco de linha ('recreio') } \\
\text { ou de pesca }\end{array}$ & $\begin{array}{l}\text { Quando o pescador não tem condições para } \\
\text { alugar um barco, ele acaba pagando frete ao } \\
\text { 'recreio' para levar a produção. Geralmente, ele } \\
\text { paga o frete após vender o peixe }\end{array}$ & $\begin{array}{l}\text { "Quando não tem barco pra levá, o jeito é pagá frete pro } \\
\text { recreio ou geleiro [barco de pesca]. (...) daí paga depois } \\
\text { que vende o peixe por lá" (M. B., lago Uauaçu, 2006) }\end{array}$ \\
\hline Jangadas & $\begin{array}{l}\text { Grandes tanques de madeira, com boias para } \\
\text { flutuação, que são rebocados por um barco. Esse } \\
\text { método de transporte foi relatado somente para } \\
\text { o lago Jari, região sul da RDS-PP }\end{array}$ & $\begin{array}{l}\text { "Aí coloca todo o peixe na jangada e vai embora rio } \\
\text { abaixo. (...) arruma tudo no jeito e leva toda a produção } \\
\text { duma veiz. Só que antes de entrá em Manaus, pára. A } \\
\text { água fica diferente por causa do rio Negro. Daí pára } \\
\text { antes de Iranduba e um caminhão vai pegá o peixe com } \\
\text { caçapa, sabe? Aquelas basqueta" (J. A., lago Jari, 2007) }\end{array}$ \\
\hline
\end{tabular}

2 Murrieta (1998), discutindo questões alimentares humanas, afirma que alimento 'reimoso' é aquele que 'faz mal' ou que 'traz o mal', principalmente de doenças que estejam 'presas' ou 'incubadas' no organismo.

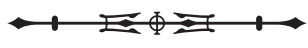


Em todos os casos, é importante que haja responsáveis pela produção acompanhando a viagem, em razão da necessidade de trocas periódicas da água (exceto para as jangadas), feitas de uma a poucas vezes ao dia, dependendo da temperatura. Busca-se manter a quantidade de água sempre no mesmo nível (abaixo da metade da 'caçapa') e a temperatura constante. Quando há incidência direta de sol no barco, por exemplo, a água deve ser trocada mais vezes para que não esquente. Há um artifício utilizado pelos pescadores para auxiliar a oxigenação: manter a 'caçapa' com um pouco menos da metade do volume de água (de 15 a 20 litros), o que faz com que os movimentos dos próprios peixes ajudem a promover as trocas gasosas junto à superfície: "Não se enche até os bico [até a borda] a caçapa; o acará-disco não pode ficá de pé. (...) Ele fica de banda [deitado] e batendo a abinha [nadadeira peitoral], e isso vai mexendo a água" (M. S., lago Ayapuá, 2006).

\section{PRODUÇÃO, COMERCIALIZAÇÃO E SUJEITOS ENVOLVIDOS}

Não destoando do contexto histórico de exploração na Amazônia, a pesca de peixes ornamentais na RDS-PP foi bem mais intensa entre as décadas de 1970 e 1990. A partir daí, diminuiu de intensidade, conforme o mercado de exportação do Amazonas se retraía frente ao comércio exterior. Com isso, o interesse pelo recurso também acabou decaindo no baixo Purus, não sendo mais esta atividade uma prioridade dos moradores locais, passando a existir somente em alguns lugares.

Em todas as entrevistas, foi mencionado que a abundância de $S$. aequifasciatus nos lagos da RDS-PP é muito alta. Todos os entrevistados do lago Ayapuá, paraná do Uauaçu e lago Uauaçu informaram que neste último local há menor abundância de acarás-discos, quando comparada aos dois anteriores.

No setor Jari, de seis entrevistas, cinco relatos de moradores e lideranças comunitárias indicaram que a pesca se dá somente na 'boca do lago' (região onde o paraná entra no lago) e em sua extremidade norte.
Quanto às questões relacionadas à variação do rendimento da pesca na área, foi difícil obter informações consistentes, pois poucas pessoas demonstraram ter conhecimento sobre o histórico da pesca na RDS-PP. Os dados seguintes foram obtidos por meio de pessoas não relacionadas à pesca. Segundo o Sr. J. A. (liderança comunitária), a última pescaria ocorreu em 2004, sendo realizada entre o paraná do Jari e a entrada do lago por um pescador do município de Manacapuru; em uma temporada de pesca, costumava-se capturar aproximadamente 20 mil acarás-discos, mesmo pescando-se apenas à entrada do lago. O Sr. M. T. (morador de Manacapuru), o qual atuou na pesca do acará-disco na área do Jari, relatou que, em 2001, foram capturados ali 12 mil exemplares. O Sr. E. A. (comunitário do Arumã) afirmou que a última pesca no lago Jussara ocorreu entre 2001 e 2002, mas não sabia informar sobre a quantidade capturada.

Já nos setores Ayapuá e Uauaçu, o auge da pesca de acará-disco na área do lago Ayapuá ocorreu no final da década de 1970 e início da seguinte. Segundo quatro relatos, nessa área, até 20 mil acarás-discos eram capturados a cada temporada.

No Setor Uauaçu, informações do IPI (dados não publicados) indicam que houve um acompanhamento da parte final de uma temporada (entre 11 e 30 de novembro de 2005) de pesca e registram a captura de 928 acarás-discos em 61 'galhadas'. Foi também documentada a morte de 37 (4\%) peixes do armazenamento até o primeiro embarque, não considerando o transporte (de 300 acarás-discos) para Manaus. Não há informações sobre a mortalidade até o final do processo, quando os peixes chegaram à empresa exportadora.

Em 2005, foram registradas duas atividades de pesca independentes. Um pescador atuou somente no início da temporada (setembro) e parou, deixando cerca de 1.500 acarás-discos presos em dois currais. $\bigcirc$ outro grupo, formado por quatro pescadores, capturou 800 exemplares.

O sistema de comercialização da produção de acará-disco variava entre os grupos que desenvolveram 
a pesca. Identificaram-se duas formas principais: uma na qual um pescador toma a iniciativa da pescaria e contrata parceiros, pagando pela prestação de serviços a partir da produção; e outra em que pescadores interessados se reúnem na forma de uma 'proto-cooperativa', onde cada um é dono dos atratores que montou e da produção que será gerada por ele, mas a pesca e a comercialização se realizam por meio de cooperação.

Há muita variação quanto aos valores pagos pelas empresas exportadoras de peixes. Geralmente, é utilizada uma classificação dos peixes a partir do padrão de colorido: são as chamadas 'fantasias', que estão baseadas principalmente na quantidade e intensidade de estrias de cor azul-esverdeada no corpo dos peixes, sobre um fundo marrom. Acarás-discos que apresentam pouca quantidade de estrias, dispostas somente nas margens do corpo, são chamados 'comuns'; peixes que apresentam uma grande quantidade de estrias, dispostas intensamente em toda a lateral do corpo, são classificados como 'royal blue', sendo essa 'fantasia' a mais valiosa. Entre estes dois extremos, são classificados subtipos intermediários, como 'royal comum' e 'royal'. A Tabela 2 apresenta as 'fantasias' e os valores declarados por três pescadores nos anos de 2004, 2006 e 2007.

Foram também registrados relatos sobre a participação dos pescadores no momento da venda, quando as empresas compradoras avaliam os peixes quanto aos padrões de colorido, o tamanho e estado físico. O pagamento ocorre após essa avaliação e uma fase de quarentena, sendo pagos somente os peixes aprovados nessa triagem, que ocorre sem a supervisão dos pescadores: estes somente são informados posteriormente sobre as quantidades e os valores a que têm direito, já descontada a perda por mortalidade.

$\mathrm{Na}$ área da RDS-PP, foram identificadas atividades de pesca de acará-disco nos lagos Jari, Ayapuá e Uauaçu, com um total de 15 pescadores envolvidos diretamente (Tabela 3).

Ainda com relação aos sujeitos sociais envolvidos, relataram-se três casos de conflitos na atividade. $\bigcirc$ mais antigo remonta ao ano de 1987, no lago Jari: segundo um

Tabela 2. Valores declarados para 'fantasias' (padrões de colorido) de acarás-discos no setor Uauaçu, RDS-PP. Os valores são dados em Reais (R\$). Legendas: SI = sem informação; * = termo utilizado para designar a venda de peixes de diferentes 'fantasias' por um único preço, geralmente intermediário entre os extremos; ** = fonte: Instituto Piagaçu (IPI, dados não publicados); estes valores foram pagos somente em uma ocasião, declarados por um pescador que possuía contato direto com uma empresa de Manaus; **** = preço pago para indivíduos bastante coloridos, tamanhos grandes e olhos vermelhos.

\begin{tabular}{c|c|c|c|c|c}
\hline Ano da declaração & Comum & Royal comum & Royal & Royal blue & 'Na embolada'* \\
\hline $2004 * *$ & 1,50 a 3,50 & 7,00 & 10,00 & até $20,00 * * * *$ & SI \\
\hline 2006 & SI & SI & SI & SI & 1,50 \\
\hline 2007 & 0,80 & 1,50 & 3,00 & 5,00 & 3,00 \\
\hline
\end{tabular}

Tabela 3. Total de pescadores que pescaram acará-disco como peixe ornamental na RDS-PP e comunidades a que pertencem. Legenda: * = pescador externo às comunidades da RDS-PP.

\begin{tabular}{c|c|c}
\hline Setor/Região & Comunidades & Número de pescadores \\
\hline Jari-Arumã/lago Jari & Santa Luzia & 2 \\
\hline \multirow{2}{*}{ Ayapuá/lago Ayapuá } & Divino Espírito Santo (Pinheiros) & 2 \\
\cline { 2 - 3 } & Nossa Senhora do Livramento (Uixi) & 5 \\
\hline Uauaçu/paraná do Uauaçu & Nova Jerusalém & 4 \\
\hline Uauaçu/lago Uauaçu & São João Batista do Uauaçu (Uauaçu) & 1 \\
\hline Município de Manacapuru, Amazonas* & - & 15 \\
\hline Total 5 & 6 & \\
\hline
\end{tabular}




antigo morador do lago (Sr. J. A.), nesse ano, um grupo de pessoas 'de fora' (não moradores da região) entrou no lago para pescar, não sendo solicitada permissão aos membros da comunidade, os quais sequer foram informados da atividade. Os moradores revoltaram-se e destruíram todos os atratores, puxando-os para fora da água.

O segundo conflito ocorreu no lago Ayapuá, no ano de 2004. Na ocasião, um pescador contratou comunitários para a construção das 'galhadas', no início do período de seca, mas não voltou para pescar, pagar o serviço ou dar satisfações. Alguns comunitários do lago também reprovaram a construção de 'galhadas' próximas às suas casas, sem o devido consentimento dos mesmos.

O terceiro conflito ocorreu no lago Uauaçu no ano de 2005. As 'galhadas' foram construídas e a pesca foi iniciada, porém a forte seca inviabilizou o uso de várias delas. $\bigcirc$ pescador desistiu da atividade e preferiu pescar peixes para consumo, com uma rede de arrasto ('arrastão'), e abandonou os viveiros com os acarás-discos que já haviam sido capturados. Os comunitários reprovaram a atitude de abandono aos peixes ornamentais e a pesca com 'arrastão': no fim, os viveiros foram revirados, soltando os acarás-discos, e o pescador foi expulso da região.

\section{DISCUSSÃO}

\section{VARIAÇÕES ESPAÇO-TEMPORAIS NA PESCA}

As informações sobre locais e abundância de $S$. aequifasciatus coincidem com dados de Crampton (1999a, 1999b), que comenta haver maior abundância de acarás-discos nos lagos do que em paranás, bem como em relação à concentração das pescarias durante a seca. Segundo Santos et al. (2006), o acará-disco vive nas margens de lagos e de rios, o que não foi mencionado por pescadores; essa ausência de informação possivelmente se deve ao fato de as áreas de estudo estarem localizadas exclusivamente em lagos. Não houve registros de pesca de disco nas margens do rio Purus, o que, provavelmente, reflete apenas a ausência da informação.
Prang (2001a, 2001b, 2007) menciona os mesmos ambientes preferenciais para o acará-disco e relata a técnica de pesca utilizada no rio Negro, com pequenos puçás, na qual os peixes são capturados individualmente nas 'galhadas' durante a noite, utilizando-se lanternas para focar os animais.

Na região do médio rio Solimões, RDS Amanã e Mamirauá, Amazonas, há relatos da pesca de acarás-discos em áreas de maracarana (Ruprectia sp., Polygonaceae) e, em alguns locais, com a construção de 'galhadas' artificiais. Nesses locais, ocorre a formação de aglomerados de maracarana, que ficam parcialmente submersos no início da seca, o que possibilita o cerco de um agrupamento dessas plantas para a captura dos peixes (Mendonça e Camargo, 2006). Esse tipo de vegetação não foi mencionado nas entrevistas, não tendo sido também observado em nenhuma das áreas de pesca do acará-disco na RDS-PP.

Há, ainda, relatos da utilização de ictiocidas (barbasco/ timbó, Lonchocarpus spp., Fabaceae) para a captura do acarádisco no Peru (Moreau e Coomes, 2007), o que não foi mencionado nas entrevistas deste estudo.

Relatos de pescadores informando a preferência da espécie por profundidades médias e pela correnteza nula ou baixa estão de acordo com observações em campo, feitas quando o nível da água ainda estava diminuindo. Em algumas ocasiões, foi possível observar que 'galhadas' parcialmente submersas e com presença de acarás-discos foram sendo abandonadas pelos peixes à medida que descia o nível da água, com ausência de discos em profundidades inferiores a 0,6 m. Somando-se a isso, Chippari-Gomes et al. (2005), comparando a tolerância à hipóxia do acará-disco (S. aequifasciatus) em relação ao acará-açu (Astronotus crassipinnis), concluíram que $S$. aequifasciatus tem menor tolerância, o que se reflete na aparente preferência da espécie por locais com melhor oxigenação da água.

Pescadores locais sugerem que o acará-disco entra na floresta inundável durante a enchente, o que corrobora dados obtidos por Crampton (1999a, 1999b) para a área da RDS Mamirauá. Porém, o argumento de alguns pescadores de que $S$. aequifasciatus se desloca em direção às cabeceiras 
dos igarapés para posteriormente ocupar a floresta alagada não pôde ser confirmado.

\section{A PESCARIA DO ACARÁ-DISCO E O CONHECIMENTO ECOLÓGICO LOCAL (LEK)}

Os pescadores demonstraram grande conhecimento quanto aos locais de ocorrência do acará-disco na RDS-PP. Segundo Leme e Begossi (2004), o conhecimento sobre os diferentes ambientes e sobre a dinâmica temporal de distribuição dos recursos pesqueiros é de extrema importância nas relações de uso dos recursos pelas populações ribeirinhas. Os pescadores também demonstraram amplo conhecimento sobre a técnica de captura e os materiais utilizados, relatando todo o processo com uma vasta riqueza de detalhes. Marques (2001) aponta o caráter utilitário desse conhecimento, julgando o saber sobre a utilidade dos materiais, as técnicas e a perícia de manipulá-los como pontos-chave para o sucesso da atividade.

O uso da técnica de ouvir e/ou sentir as vibrações dos peixes quando se movimentam entre os ramos da vegetação submersa revelou-se extremamente interessante. Costa-Neto et al. (2002) relacionam o conhecimento sobre o comportamento dos peixes por pescadores a etnocategorias ('peixe que ronca', 'peixe que anda', 'peixe que caminha à noite', 'peixe que bufa' e 'peixe de cardume'), vinculando-as aos fenômenos etológicos observados (produção de som, migração, formação de cardumes e comportamento nictemeral).

Marques (2001) também aponta a existência do que chama de "habilidosas manipulações comportamentais", igualmente baseadas na observação de eventos etológicos, e empregadas visando ao sucesso nas pescarias. Segundo o autor, muitas dessas habilidades relacionam-se com a percepção de estímulos sonoros e/ou vibratórios e, portanto, têm base bioacústica.

Pode ser citada, também na pesca, a técnica desenvolvida para a quantificação de pirarucus (Arapaima gigas, Arapaimatidae) nos lagos da RDS Mamirauá. Trata-se da observação do comportamento de subir periodicamente à tona para respirar, registrada por pescadores, que permite a estes detectarem visual ou auditivamente a espécie, realizando a contagem. Comparações entre essas estimativas e experimentos controlados mostraram a acurácia das contagens, sendo que esta ferramenta é hoje utilizada no manejo sustentável da espécie na RDS Mamirauá e replicada em vários outros lugares da Amazônia (Castello, 2004; Viana et al., 2007).

Tendo bases bioacústicas, a habilidade dos pescadores de acará-disco na RDS-PP chama a atenção para dois fatos: (1) a utilização de uma ferramenta acessória, no caso um remo, para causar uma perturbação (por meio do contato com os ramos), suficiente para que haja a movimentação dos acarás-discos na 'galhada'; (2) a percepção de que o mergulho pode ser mais eficiente, pois parece possibilitar a detecção da presença de quantidades muito pequenas de acarás-discos. Trata-se, portanto, de uma combinação entre os sentidos de audição e tato. Quando questionados sobre a eficiência da técnica e sobre a possibilidade de quantificação dos acarás-discos nas 'galhadas', surpreendentemente obtivemos respostas positivas: "Pra sabê se tem muito ou pouco? Conforme o estrondo, a zuada, né [a movimentação dos peixes, o barulho, a vibração] já dá pra calculá! Dá pertinho da quantia (...), já cansei de chutá e dá certo! Conforme o estrondo, o cara calcula e dá certo" (S. R., paraná do Uauaçu, 2007).

Questionados quanto ao fato de outras espécies também poderem criar essa vibração, os pescadores afirmaram que a experiência permite diferenciar a 'zoada' produzida pelos acarás-discos da fornecida pelos demais peixes, alegando ser um barulho bastante característico. Experimentos controlados de bioacústica poderão testar objetivamente essa hipótese, o que deverá ser realizado em futuro próximo.

Há pouco mais de uma década, os pescadores de acará-disco da RDS-PP vêm construindo atratores de pesca, visando à otimização do esforço de captura. Anteriormente, a pesca ocorria com um dispêndio significativo de energia (esforço físico) e tempo, com a 
remoção das grandes copas de árvores caídas nas margens dos lagos. Além disso, os ambientes disponíveis para pesca eram relativamente raros e apresentavam dificuldades logísticas, devido ao emaranhado dos galhos de árvores.

Marques (2001), ao escrever sobre pescadores brejeiros de Marituba (Alagoas), aponta que uma "cognição compartilhada" (resultante do conjunto de conhecimentos sobre a espécie) leva os pescadores a adaptações comportamentais, com o surgimento de táticas e estratégias, em um admirável contexto presa/predador, onde um conjunto de instrumentalidade material torna-se necessário.

Os ramos utilizados como matéria-prima para os atratores de pesca são cortados de arbustos vivos, havendo casos em que são cortados somente alguns ramos, e outros em que a copa inteira é retirada, cortada abaixo da primeira ramificação. Pelo que foi possível observar, de arbustos maiores são retirados somente alguns ramos, e plantas de pequeno porte (em torno de $2 \mathrm{~m}$ de altura) podem ser cortadas inteiras. Há um predomínio marcante na utilização do araçá para esse fim, tanto nas observações quanto nas entrevistas. Crampton (1999a, 1999b) ressalta a importância da conservação da floresta de restinga como hábitat não só para o acará-disco, mas também para muitos outros peixes da várzea. Mendonça e Camargo (2006) propõem que a construção de 'galhadas' artificiais, utilizando ramos de vegetação morta, pode ser uma alternativa menos destrutiva para a região das reservas Amanã e Mamirauá.

Quando questionados sobre os possíveis impactos da retirada de vegetação marginal dos lagos, os entrevistados alegaram que o araçá e o carauaçu apresentam rápida regeneração, não havendo indícios de morte das árvores podadas, tampouco daquelas que foram cortadas completamente. Buscando responder a essa questão, foi iniciado o monitoramento de 100 indivíduos de araçá que haviam sido podados ou cortados para a construção dos atratores experimentais. Após um ano, houve a regeneração de $98 \%$ dessas plantas, inclusive daquelas cuja copa havia sido retirada completamente. Porém, estudos mais aprofundados necessitam ser realizados para avaliar a sustentabilidade dessa forma de utilização da vegetação, evitando uma transferência de impactos da atividade de pesca.

Os entrevistados relatam uma escolha criteriosa de materiais e da forma de disposição dos ramos para a construção das 'galhadas'. Segundo eles, a disposição final do atrator é fundamental para a sua eficiência. Bolding et al. (2004), em uma revisão sobre a utilização de atratores artificiais, discutem vários fatores que podem afetar sua eficiência e rendimento na pesca (formas, dimensões, profundidade, materiais etc.), destacando-se, entre eles, a quantidade e o tamanho dos espaços intersticiais disponíveis nos atratores. Segundo esses autores, tais características podem influenciar a composição das espécies e o tamanho dos grupos que poderão ser atraídos para a estrutura. Essas informações estão de acordo com o observado na pesca de acará-disco, justificando a preferência pelo araçá, em função das características físicas e de arquitetura dos ramos, que são especialmente adequadas para a formação de espaços intersticiais como refúgio para os peixes. Esses autores também discutem vantagens econômicas relacionadas à utilização de determinadas estruturas, como as montadas com ramos de vegetação natural, que constituem excelentes substratos para a atração de peixes. As principais vantagens em relação a estruturas sintéticas (concreto, pneus, polímeros plásticos etc.) são a variedade de espaços disponibilizados para a colonização e o baixo custo de produção.

Os pescadores também apontam como crucial para o sucesso da pesca a escolha dos locais para a construção das 'galhadas'. Além disso, questões logísticas são consideradas, como distâncias para carregar a matériaprima e a profundidade da água no local, para que não haja a perda ou ineficiência do atrator.

Portanto, a utilização de atratores de pesca para a captura de acará-disco obedece a dois conjuntos de variáveis: um ecológico, regido para o sucesso na captura, e outro econômico, no qual a questão de viabilidade logística também é avaliada.

Leme e Begossi (2004), em estudo sobre pescadores do rio Negro, relatam que a escolha dos locais de pesca 
é feita pela experiência pessoal e pela capacidade logística de cada pescador. Assim, pescadores que possuem canoas motorizadas levarão vantagem sobre os que se deslocam com canoas a remo, por exemplo, em função da maior capacidade de deslocamento e de carregamento de matéria-prima até o local selecionado para a construção do atrator.

Embora o uso de atratores de pesca apresente diversos benefícios, Bohnsack et al. (1991) mencionam que o uso de hábitats artificiais para fins pesqueiros pode resultar em um aumento na mortalidade por pesca, devido ao crescimento da eficiência no acesso às presas, o que geraria um custo ambiental mais elevado. Nesse sentido, há a necessidade de estabelecimento de critérios para a utilização de atratores. Se, por um lado, há uma otimização do processo de captura de peixes no hábitat artificial, deve haver também a preocupação de essa técnica não estar servindo para agravar problemas de sobreexplotação, que podem ser: (1) a captura sem critérios de grande quantidade de acará-disco, resultante das altas concentrações nos atratores; (2) a utilização indiscriminada do bycatch (fauna associada à espécie-alvo da pesca), no caso, peixes comestíveis de interesse comercial. Trata-se, portanto, de uma questão de gestão pesqueira, na qual uma análise de custo-benefício deve ser considerada.

Seguindo as etapas da pescaria, após o acondicionamento dos acarás-discos em 'caçapas' plásticas, é costume os pescadores adicionarem um pouco de sal na água. Segundo Mendonça e Camargo (2006), o sal também foi utilizado como agente sanitário no transporte de peixes na região do médio Solimões.

A estocagem em tanques de madeira é semelhante à descrita por Mendonça e Camargo (2006) para a região da RDS Mamirauá, e diferente do apresentado por Prang (2001a, 2007) para o rio Negro, onde os tanques são confeccionados com telas plásticas do tipo 'mosquiteiro'. Quanto à disposição dos tanques, a escolha de locais com circulação de água e ausência de capim é condizente com as conclusões de Chippari-Gomes et al. (2005), que demonstram uma baixa tolerância à hipóxia por S. aequifasciatus.
Quanto à densidade de acarás-discos nas 'caçapas', fica evidente a preocupação dos pescadores em manter a oxigenação da água para que a mortalidade seja baixa. Essa problemática vem ao encontro do alerta de Waichman et al. (2001), que relataram altas taxas de mortalidade na captura e no transporte de peixes ornamentais da bacia amazônica, grande parte da qual provavelmente induzida por estresse fisiológico. Nesse sentido, um dos fatores que podem reduzir o estresse e a mortalidade é a qualidade da água. Isso poderia ser evitado pela melhoria das condições de captura e de transporte dos animais e pelo treinamento das pessoas envolvidas (Leite e Zuanon, 1991). Segundo Lewbart (2001), apesar da sofisticação de técnicas e diagnósticos modernos, não há como fugir da realidade, onde princípios coerentes de manejo devem ser levados em consideração para uma gestão eficiente e sustentável da pesca.

O sistema de armazenagem e transporte dos acarás-discos na área da RDS-PP está de acordo com o mencionado por Prang (2001a, 2001b, 2007), no qual a venda e o transporte da produção estão relacionados com as condições socioeconômicas dos pescadores e/ou atravessadores. Porém, não foram encontradas citações sobre a utilização de jangadas para o transporte de acarásdiscos em outros locais, além do lago Jari, sul da RDS-PP.

Ruddle (2000) discute a elaboração de novas tecnologias e estratégias de pesca, desenvolvidas por pescadores com base no LEK, onde se destacam alta especificidade e eficiência para a captura de espécies-alvo, incluindo o poder de predição (de tempo, local, ciclo lunar etc.) para um bom rendimento da pesca. Nesse sentido, os pescadores de acarás-discos utilizaram informações sobre a espécie (áreas de ocorrência, sazonalidade, abundância, locais, comportamentos etc.) e desenvolveram um método bastante eficiente de pesca.

Marques (2001) relata que o sucesso do 'pescador/ predador' depende fortemente de manipulações do conhecimento acerca de cadeias tróficas, uma vez que isso fará com que utilize o item alimentar (isca) correto, otimizando o esforço da pesca. Esse fato ocorreu com a 
pesca do acará-disco, porém no contexto da seleção de hábitat, no qual o amplo conhecimento ecológico sobre a espécie levou os pescadores a desenvolverem um atrator ('hábitat/galhada') eficiente, a ponto de substituir completamente a antiga técnica.

Com isso, torna-se evidente a importância do LEK nesse contexto de pesca. Assim como o método de contagem de pirarucus desenvolvido por Castello (2004) em Mamirauá, o presente estudo buscou entender o conhecimento dos pescadores sobre a espécie para aplicá-lo, também de forma integrada, à elaboração de estratégicas para uma exploração responsável e sustentável do acará-disco como recurso pesqueiro.

\section{SISTEMA DE PRODUÇÃO}

Os dados mostram que a pesca de acará-disco na RDS-PP é esporádica e incipiente, sendo realizada apenas durante a seca e, na maioria das vezes, sob demanda dos compradores. Nesse contexto, a grande dependência da pesca em relação ao mercado e a oscilação na demanda de ano para ano dificultam o estabelecimento dessa atividade em áreas nas quais a pesca ornamental é quase exclusivamente baseada na captura de uma única espécie, como é o caso da RDS-PP.

Leme e Begossi (2004) apontam a concorrência com outras áreas de exploração, a retração do mercado mundial e a escassez de espécies muito exploradas como causas da migração da pesca de peixes ornamentais para a pesca de espécies comestíveis por 'piabeiros' do rio Negro. Esse não é o caso da RDS-PP, onde a pesca de acará-disco não constitui a atividade exclusiva ou principal dos pescadores, mas sim uma fonte de renda complementar de algumas famílias, inclusive pela grande sazonalidade que apresenta.

Quanto às relações entre os sujeitos envolvidos, de uma forma geral, foram identificadas características semelhantes às descritas para a pesca de peixes ornamentais no rio Negro (Prang, 2001a) e para outras áreas do estado do Amazonas (Prang, 2007), envolvendo três categorias de pescadores na RDS-PP (Tabela 4). Considerando as atividades do lago Jari e Ayapuá, os sujeitos envolvidos podem ser caracterizados como 'pescador patrão' e 'pescador cliente/coletor'. Já no lago Uauaçu, também foram registrados 'pescadores autônomos'.

A Figura 3 mostra as categorias de pescadores e sua rede de relacionamento na RDS-PP, baseadas em Prang (2001a, 2001b), que discute as relações de aviamento entre 'piabeiros' do rio Negro. Esse autor conclui que as formas de negociação podem ser coercivas ou amigáveis, podendo ser influenciadas ou mediadas por relações de parentesco entre os envolvidos.

Quanto aos valores pagos pelos acarás-discos, há grande variação nas informações. $O$ preço dos peixes pode variar de acordo com os padrões de colorido ('fantasias'), o tamanho e as condições físicas (integridade das nadadeiras, ausência de ferimentos) de cada exemplar. Chama a atenção o fato de que os valores declarados para o ano de 2004 (de $\mathrm{R} \$ 1,50$ a $\mathrm{R} \$ 20,00$ por unidade) dizem respeito a somente um pescador. Esse informante declarou ter contato direto com uma empresa em Manaus e que estes preços foram negociados em apenas uma ocasião. Nas entrevistas, de forma geral, foram citados valores entre $\mathrm{R} \$ 0,80$ e 1,50 por peixe.

Tabela 4. Categorias de pescadores de acará-disco na RDS-PP, com suas características, baseadas em Prang (2001a).

\begin{tabular}{c|l}
\hline Categoria & \multicolumn{1}{c}{ Características } \\
\hline $\begin{array}{c}\text { Pescador } \\
\text { patrão }\end{array}$ & $\begin{array}{l}\text { Agente intermediário da cadeia produtiva, que } \\
\text { negocia a produção dos clientes/coletores } \\
\text { e revende para as empresas exportadoras. } \\
\text { atuar como pescador. Geralmente, adquire } \\
\text { condições (material e ajuda de custo) das } \\
\text { empresas e utiliza-se delas para negociar com } \\
\text { os clientes/coletores na forma de aviamento }\end{array}$ \\
\hline Pescador & $\begin{array}{l}\text { Pescador local que pesca e/ou acompanha o } \\
\text { patrão nas pescarias, servindo a temporada } \\
\text { para incrementar a renda familiar. Em termos } \\
\text { econômicos, frequentemente dependente } \\
\text { totalmente do patrão }\end{array}$ \\
\hline Pescador & $\begin{array}{l}\text { É o pescador que entrega sua produção } \\
\text { diretamente à empresa exportadora. } \\
\text { Geralmente, possui alguma condição e/ou } \\
\text { negocia condições com a empresa (como } \\
\text { material e ajuda de custo para iniciara atividade) }\end{array}$ \\
\hline
\end{tabular}

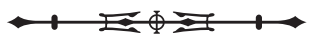




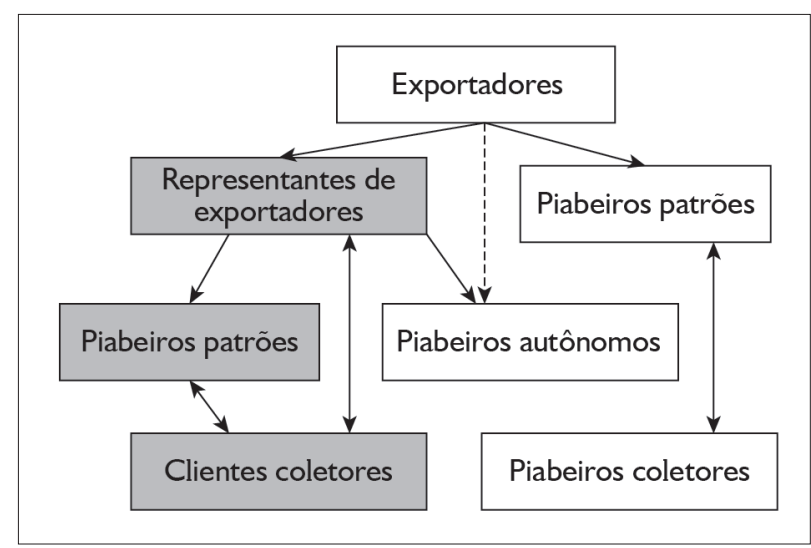

Figura 3. Esquema das relações encontradas na cadeia produtiva da pesca de peixes ornamentais no estado do Amazonas (modificado de Prang, 2001a, 2007). As setas com sentido único indicam uma relação de transação monetária e as com duplo sentido indicam relações que podem envolver sistema de aviamento. Os sujeitos e relações representados em caixas sombreadas não foram registrados nas atividades de pesca do acará-disco na RDS Piagaçu-Purus, e a linha pontilhada representa uma nova relação identificada naquela área.

Outra forma de valoração foi relatada em algumas entrevistas, que é o pagamento 'na embolada'. Esse termo faz referência ao pagamento, por um mesmo preço unitário, por um lote de peixes contendo indivíduos de diferentes tamanhos e padrões de colorido (Tabela 2). Essa tática certamente é vantajosa para os compradores, dependendo da quantidade e/ou qualidade dos peixes oferecidos, quando valores um pouco mais altos, pagos para indivíduos pouco interessantes, seriam compensados pelos grandes lucros obtidos com a venda dos melhores exemplares.

Mendonça e Camargo (2006) também mencionam o pagamento dos peixes a partir de categorias préestabelecidas. Entretanto, mencionam que o patrão local paga as despesas da pesca a uma média de $R \$$ 1,00 por acará-disco, o que equivale ao pagamento 'na embolada' da RDS-PP.

Os valores diferenciados para os diversos padrões de cor decorrem do interesse que o mercado internacional de acarás-discos tem por peixes de diferentes localidades amazônicas. Atendo-se a essa procura, as empresas exportadoras priorizam áreas de captura, podendo alternar as áreas de exploração anualmente, o que faz com que os valores pagos variem de acordo com os interesses das empresas.

Dois pescadores entrevistados relataram que a avaliação de sua produção é realizada nas empresas. Informaram também que o pagamento é efetivado somente após um período de quarentena, sendo pagos somente os peixes que passam por essa triagem; porém, em vários relatos, foi dito que o número de peixes pagos havia sido menor que o número de peixes entregues.

Temos, portanto, dois fatores atuando como problemática na cadeia produtiva do acará-disco da RDS-PP: (1) a demanda do mercado, principalmente o internacional; (2) o enfraquecimento do produtor frente ao sistema de classificação e comercialização do seu produto perante as empresas. No primeiro caso, essa regência pode se constituir como um problema ambiental e de integridade dos estoques pesqueiros enquanto atua como controladora dos locais a serem explorados com alta intensidade, bem como da exploração direcionada a uma ou a poucas 'fantasias' mais valiosas economicamente. Já no segundo contexto, a falta de condições justas de controle na classificação em 'fantasias' e, consequentemente, no preço dos peixes, faz com que os direitos a uma comercialização equânime sejam violados. Esses fatores apontam para a falta de organização dos pescadores. É imprescindível que haja um investimento na organização social deste grupo, para que possam defender seus direitos, em busca de um comércio justo (fair trade) junto ao mercado internacional de peixes ornamentais.

Considerando o modo de vida da população da RDS-PP, caracterizado pelo uso múltiplo dos recursos naturais, coma grande maioria dos comunitários desenvolvendo atividades diversas segundo a sazonalidade do ciclo hidrológico, reforça-se o potencial de utilização da pesca do acarádisco como uma forma de incremento na renda familiar.

Também é possível observar a incipiência da pesca do acará-disco, relativa à população total de cerca de 5.000 pessoas vivendo na RDS-PP. Em várias outras regiões da reserva, foi mencionada uma grande abundância de acarás- 
discos, potencial não explorado por falta de conhecimento sobre esse tipo de atividade econômica, as possibilidades do mercado, de contato com exportadores, de materiais ou de técnicas de pesca.

\section{CONFLITOS}

Mesmo sem uma pergunta específica sobre conflitos no protocolo de entrevista, foi possível identificar esse problema quando se conversou sobre as relações sociais envolvendo a pesca (participação de comunitários, lucro da atividade etc.), tanto com pescadores como com comunitários não pescadores.

De forma geral, podemos discutir esses conflitos à luz dos conceitos de 'pesqueiros' e 'territórios' na pesca, apresentados por Begossi (2004). A denominação de 'pesqueiros' está relacionada às áreas onde agregados (locais com maior abundância) do recurso em questão podem ser encontrados. Quando há algum tipo de conflito no uso dessas áreas, pode-se caracterizar, então, um território, sendo interpretado como "um espaço que foi ou está sendo apropriado por algum indivíduo, grupo, ou comunidade, sob formas de defesa ou de regras de uso, ou sob conflitos de uso" (Begossi, 2004, p. 225).

Foi possível observar, portanto, os seguintes cenários: (1) a utilização do território por agentes externos, havendo a demanda por um 'ressarcimento' por (a) uso do espaço, (b) uso do recurso ou (c) uso de ambos; (2) a competição pelo uso do recurso em um mesmo território.

No caso do lago Jari, em 1987, até comunitários que não estavam pescando acarás-discos destruíram as 'galhadas' preparadas por terceiros em sua área de pesca, em um ato identificado como defesa do território da comunidade. $O$ incidente no lago Ayapuá mostrou semelhante reprovação de parte de comunitários não pescadores de acará-disco diante da construção, sem consentimento, de 'galhadas' junto a suas casas. Os dois eventos refletem o cenário (1a).

Ainda no lago Ayapuá, houve casos de reprovação da atividade de pesca da espécie por comunitários que não receberam pela prestação de serviços (construção das 'galhadas'). Essa situação caracteriza o cenário (1b), pois, se esses comunitários trabalharam para a construção das 'galhadas', então consentiam a exploração do acará-disco dentro do território.

A ocorrência no lago Uauaçu, onde os acarásdiscos dos viveiros foram abandonados e o foco da pesca, redirecionado a espécies comestíveis, pode ser considerada no cenário (1c), dada a preocupação da comunidade (ou de parte de seus membros) com a conservação do recurso (o acará-disco) dentro de seu território. Mas houve também uma alteração nas relações entre pescadores. Enquanto pescavam acarás-discos, aqueles pescadores de fora da comunidade não estavam competindo com os comunitários pelos peixes comestíveis; a mudança da espécie-alvo da pesca, porém, desencadeou uma competição com os comunitários, que se sentiram prejudicados com a entrada de pescadores 'não comunitários' na área. Além disso, os forasteiros utilizaram a rede de arrasto, apetrecho considerado predatório pelos comunitários, a qual apresenta eficiência muito maior na exploração do recurso em relação à obtida pela comunidade. Este evento se enquadra no cenário (2).

Em todos os casos de conflitos registrados na RDS-PP, foi possível identificar a preocupação dos que se sentiram prejudicados em um contexto de duas variáveis de competição, espaço (território) e recurso. Isso vai ao encontro do indicado por Silva (2007), ao apontar, sob uma perspectiva ambiental, a simbologia dada ao território como uma interação entre aspectos econômicos e sociais - respectivamente, recursos e territórios - como determinações de poder.

\section{CONSIDERAÇÕES FINAIS}

Fica evidente o conhecimento ecológico local (LEK) apresentado pelos pescadores de acará-disco na área da RDS-PP, havendo uma rica e detalhada gama de táticas e adaptações metodológicas, com o objetivo de otimizar o esforço da pesca. 
As técnicas desenvolvidas pelos pescadores locais - detecção de acará-disco nas 'galhadas' e construção de atratores - indicam, conforme declarações dos comunitários, aumento na eficiência da pesca, a ponto de terem substituído completamente a antiga técnica baseada na exploração de 'galhadas' naturais. Isso poderá subsidiar estratégias para programas de monitoramento, em que avaliações de esforço e do rendimento dessa modalidade de pesca poderão ajudar a prevenir uma sobre-explotação do recurso.

A pesca do acará-disco é incipiente na área da RDSPP e fica evidente a carência de organização da cadeia produtiva, sendo necessário propiciar o comércio justo da produção e a sustentabilidade no uso desse recurso natural, resultando em melhoria da qualidade de vida para as comunidades da reserva.

É conhecida a forte característica de uso múltiplo dos recursos pelas comunidades ribeirinhas da Amazônia, sobretudo as que residem na várzea. Por isso, tratar a organização de uma cadeia de produção de forma segmentada torna-se um desafio. Essa organização implica a necessidade de se desenvolver atividades visando ao entendimento de toda a rede de produção. Isso, porém, é um processo longo e custoso, no qual se devem respeitar os processos locais e suas escalas de tempo e espaço.

É exatamente nesse processo que está a oportunidade de se combinar as informações técnicas, geralmente advindas de meios externos, e o LEK, processos genuinamente endógenos, visando à construção de uma estratégia suficientemente robusta para enfrentar as demandas organizacionais de produção, comercialização e gerenciamento. Trata-se, portanto, de uma questão de gestão pesqueira, segundo a qual a combinação de saberes locais e acadêmicos venha a somar, proporcionando a construção de uma estratégia de exploração sustentável - ecológica, econômica e socialmente - do acará-disco na RDS-PP.

Acreditamos que o presente estudo poderá contribuir para a construção de uma atividade de exploração sustentável, criada verdadeiramente de forma participativa. É de extrema importância realizar o levantamento dos conhecimentos e processos já empregados localmente na atividade, para que haja a possibilidade de se desenvolverem sistemas de manejo a partir dos interesses e da capacidade de cada comunidade, respeitando suas diferenças e valorizando iniciativas endógenas. Somente assim haverá, como resultado, uma verdadeira gestão compartilhada, com sistemas gerenciais locais legitimados.

\section{AGRADECIMENTOS}

Aos comunitários da RDS-PP, em especial aos pescadores Assis, Jeremias e Mário, pela indispensável ajuda em campo; à Marina Vieira, aos dois revisores anônimos, pelos comentários ao manuscrito, e a Boris Marioni, pela confecção do mapa. Este estudo recebeu recursos financeiros do Conselho Nacional de Desenvolvimento Científico e Tecnológico (CNPq) (MCT/CNPq/SEAP-PR/ CT-Infra n. 016/2006, processo n. 408805/2006-4 e Bolsa de Mestrado de F. R.), da Fundação Gordon and Betty Moore, por meio da Wildlife Conservation Society (WCS), e do Instituto Piagaçu (IPI). Recebeu, ainda, apoio do Centro Estadual de Unidades de Conservação do Amazonas (CEUC/SDS-AM). F. R. recebe bolsa de pesquisa pelo convênio IPI - Instituto de Desenvolvimento Sustentável Mamirauá (IDSM), por meio de recursos financeiros do Ministério da Ciência, Tecnologia e Inovação (MCTI). J. Z. recebe bolsa de produtividade em pesquisa do CNPq (Processo 307464/2009-1).

\section{REFERÊNCIAS}

ANJOS, H. D. B.; AMORIM, R. M. S.; SIQUEIRA, J. A.; ANJOS, C. R. Exportação de peixes ornamentais do estado do Amazonas, Bacia Amazônica, Brasil. Boletim do Instituto de Pesca, São Paulo, v. 35, n. 2, p. 259-274, 2009.

BAILEY, K. D. (Ed.). Methods of social research. New York: The Free Press, 1987. 588 p.

BEGOSSI, A. Áreas, pontos de pesca, pesqueiros e territórios na pesca artesanal. In: BEGOSSI, A.; LEME, A.; SEIXAS, C. S.; CASTRO, F.; PEZZUTI, J.; HANAZAKI, N.; PERONI, N.; SILVANO, R. A. M. (Eds.). Ecologia de pescadores da Mata Atlântica e da Amazônia. São Paulo: HUCITEC, 2004. p. 223-253.

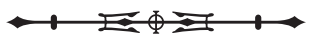


BEGOSSI, A.; HANAZAKI, N.; PERONI, N.; SILVANO, R. A. M. Estudos de ecologia humana e etnobiologia: uma revisão sobre usos e conservação. In: ROCHA, C. F. D.; BERGALLO, H. G.; VAN SLUYS, M.; ALVES, M. A. S. (Eds.). Biologia da conservação: essências. São Carlos: RiMa Editora, 2006. p. 537-562.

BERKES, F.; MAHON, R.; MCCONNEY, P.; POLLNAC, R.; POMEROY, R. Gestão da pesca de pequena escala: diretrizes e métodos alternativos. Porto Alegre: Editora da FURG, 2006.

BOHNSACK, J. A.; JOHNSON, D. L.; AMBROSE, R. F. Ecology of artificial reef habitats and fishes. In: SEAMAN JR., W.; SPRAGUE, L. M. (Eds.). Artificial habitats for marine and freshwater fisheries. Londres: Academic Press, 1991. p. 61-107.

BOLDING, B.; BONAR, S.; DIVENS, M. Use of artificial structure to enhance angler benefits in lakes, ponds, and reservoirs: a literature review. Reviews in Fisheries Science, v. 12, n. 1, p. 75-96, 2004.

BRASIL. Ministério da Pesca e Aquicultura/Ministério do Meio Ambiente. Instrução Normativa Interministerial n. 1, de 3 de janeiro de 2012. Estabelece normas, critérios e padrões para a explotação de peixes nativos ou exóticos de águas continentais com finalidade ornamental ou de aquariofilia. Diário Oficial da União, Brasília, 4 jan. 2012. Disponível em: <http://www.mpa.gov.br/images/Docs/INs/ IN_2012/INI\%20n\%C2\%BA\%20001\%20-\%20Explotacao\%20 peixes\%20nativos\%20exoticos\%20aguas\%20continentais.pdf >. Acesso em: 10 dez. 2013.

BRASIL. Lei n. 9.985, 18 jul. 2000. Regulamenta o art. 225, § $1^{\circ}$, incisos I, II, III e VII da Constituição Federal, institui o Sistema Nacional de Unidades de Conservação da Natureza e dá outras providências. Diário Oficial da União, 19 jul. 2000. Disponível em: <http://www.planalto.gov.br/ccivil_03/leis/19985.htm>. Acesso em: 10 dez. 2013.

CASTELLO, L. A method to count pirarucu Arapaima gigas: fishers, assessment and management. North American Journal of Fisheries Management, v. 24, p. 379-389, 2004.

$\mathrm{CHAO}, \mathrm{N}$. L. The fishery, diversity, and conservation of ornamental fishes in the Rio Negro Basin, Brazil - a review of Project Piaba (198999). In: CHAO, N. L.; PETRY, P.; PRANG, G.; SONNESCHIEN, L.; TLUSTY, M. (Eds.). Conservation and management of ornamental fish resources of the Rio Negro Basin, Amazonia, Brazil - Project Piaba. Manaus: Editora da Universidade do Amazonas, 2001. p. 161-204.

CHAO, N. L. Conservation of Rio Negro ornamental fishes. Tropical Fish Hobbyist, v. 41, n. 5, p. 99-114, 1993.

CHAO, N. L.; PRANG, G.; PETRY, P. Project Piaba - maintenance and sustainable development of ornamental fisheries in the Rio Negro Basin, Amazonas, Brazil. In: CHAO, N. L.; PETRY, P.; PRANG, G.; SONNESCHIEN, L.; TLUSTY, M. (Eds.). Conservation and management of ornamental fish resources of the Rio Negro Basin, Amazonia, Brazil - Project Piaba. Manaus: Editora da Universidade do Amazonas, 2001. p. 3-6.
CHIPPARI-GOMES, A. R.; GOMES, L. C.; LOPES, N. P.; VAL, A. L.; ALMEIDA-VAL, V. M. F. Metabolic adjustments in two Amazonian cichlids exposed to hypoxia and anoxia. Comparative Biochemistry and Physiology, Part B, Biochemistry \& Molecular Biology, v. 141, n. 3, p. 347-355, 2005.

COSTA-NETO, E. M.; DIAS, C. V.; MELO, M. N. O conhecimento ictiológico tradicional dos pescadores da cidade de Barra, região do médio São Francisco, estado da Bahia, Brasil. Acta Scientiarum, v. 24, n. 2, p. 561-572, 2002.

CRAMPTON, W. G. R. The impact of the ornamental fish trade on the Discus Symphysodon aequifasciatus: a case study from floodplain forests of Estação Ecológica Mamirauá. In: PADOCH, C.; AYRES, J. M.; PINEDO-VASQUEZ, M.; HENDERSON, A. (Eds.). Várzea: diversity, development, and conservation of Amazonia's whitewater floodplains. Bronx: The New York Botanical Garden Press, 1999a. p. 29-44.

CRAMPTON, W. G. R. Plano de manejo preliminar para o uso sustentável de peixes ornamentais na Reserva Mamirauá. In: QUEIROZ, H. L.; CRAMPTON, W. G. R. (Eds.). Estratégias para manejo de recursos pesqueiros na Reserva de Desenvolvimento Sustentável Mamirauá. Brasília: MCT-CNPq/Sociedade Civil Mamirauá, 1999b. p. 159-176.

INSTITUTO BRASILEIRO DO MEIO AMBIENTE E DOS RECURSOS NATURAIS RENOVÁVEIS (IBAMA). Instrução Normativa n. 204, de 22 de Outubro de 2008. Estabelece normas, critérios e padrões para a exploração com finalidade ornamental e de aquariofilia de exemplares vivos de raias nativas de água continental, Família Potamotrygonidae. Brasília: MMA, 2008. 8 p. Disponível em: <http://www.ibama.gov.br/documentos-recursos-pesqueiros/ instrucao-normativa >. Acesso em: $10 \mathrm{dez} .2013$.

LEITE, R. G.; ZUANON, J. A. S. Peixes ornamentais - aspectos de comercialização, ecologia, legislação e propostas de ações para um melhor aproveitamento. In: VAL, A. L.; FIGLIUOLO, R.; FELDBERG, E. (Eds.). Bases científicas para estratégias de preservação e desenvolvimento da Amazônia: fatos e perspectivas. Manaus: INPA, 1991. v. 1, p. 327-331.

LEME, A. S.; BEGOSSI, A. Uso de recursos por ribeirinhos no médio rio Negro. In: BEGOSSI, A.; LEME, A.; SEIXAS, C. S.; CASTRO, F.; PEZZUTI, J.; HANAZAKI, N.; PERONI, N.; SILVANO, R. A. M. (Eds.). Ecologia de pescadores da Mata Atlântica e da Amazônia. São Paulo: HUCITEC, 2004. p. 89-148.

LEWBART, G. A. Veterinary medicine and Amazon fishes. In: CHAO, N. L.; PETRY, P.; PRANG, G.; SONNESCHIEN, L.; TLUSTY, M. (Eds.). Conservation and management of ornamental fish resources of the Rio Negro Basin, Amazonia, Brazil - Project Piaba. Manaus: Editora da Universidade do Amazonas, 2001. p. 265-277.

LIMA, A. O. Aquicultura ornamental: políticas públicas dirigidas podem colocar o Brasil junto aos maiores produtores mundiais. Panorama da Aquicultura, p. 58-59, maio-jun. 2004.

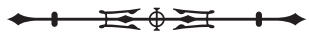


MARQUES, J. G. W. Pescando pescadores: ciência e etnociência em uma perspectiva ecológica. 2. ed. São Paulo: Núcleo de Apoio à Pesquisa sobre Populações Humanas e Áreas Úmidas Brasileiras-USP, 2001.

MCGRATH, D. G. Preliminary investigation of the trade in extrative products in the Brazilian Amazon. Final report submitted to the World Wildlife Fund. Washington: WWF, 1990.

MENDONÇA, M.; CAMARGO, M. Etnoecologia da produção de peixes ornamentais num sector do médio rio Solimões, FLONA de Tefé e Reservas Mamirauá e Amanã - estado do Amazonas. Uakari, v. 2, n. 1, p. 53-61, 2006.

MOREAU, M. A.; COOMES, O. T. Aquarium fish exploitation in western Amazonia: conservation issues in Peru. Environmental Conservation, v. 34, n. 1, p. 12-22, 2007.

MURRIETA, R. S. S. O dilema do papa-chibé: consumo alimentar, nutrição e práticas de intervenção na Ilha de Ituqui, baixo Amazonas, Pará. Revista de Antropologia, v. 41, n. 1, p. 97-150, 1998.

PRANG, G. An industry analysis of the freshwater ornamental fishery with particular reference to the supply of Brazilian freshwater ornamentals to the UK market. Uakari, v. 3, n. 1, p. 7-51, 2007.

PRANG, G. A caboclo society in the Middle Rio Negro basin: ecology, economy and history of an ornamental fishery in the state of Amazonas, Brazil. 2001. 300 f. Tese (Doutorado em Antropologia) - Wayne State University, Detroit, 2001 a.

PRANG, G. Aviamento and ornamental fishery of the Rio Negro, Brazil: implications for sustainable resource use. In: CHAO, N. L.; PETRY, P.; PRANG, G.; SONNESCHIEN, L.; TLUSTY, M. (Eds.). Conservation and management of ornamental fish resources of the Rio Negro Basin, Amazonia, Brazil - Project Piaba. Manaus: Editora da Universidade do Amazonas, 2001b. p. 43-73.
REIS, R. E.; KULLANDER, S. O.; FERRARIS, C. J. Check list of the freshwater fishes of South and Central America. Porto Alegre: EdiPUCRS, 2003.

RUDDLE, K. Systems of knowledge: dialogue, relationships and process. Environment, Development and Sustainability, v. 2, n. 3-4, p. 277-304, 2000.

SANTOS, G. M.; FERREIRA, E. J. G.; ZUANON, J. A. S. Peixes comerciais de Manaus. Manaus: IBAMA/PróVárzea, 2006.

SILVA, C. N. A percepção territorial-ambiental em zonas de pesca. Boletim do Museu Paraense Emílio Goeldi. Ciências Humanas, v. 2, n. 3, p. 25-32, 2007.

SILVANO, R. A. M. Pesca artesanal e etnoictiologia. In: BEGOSSI, A.; LEME, A.; SEIXAS, C. S.; CASTRO, F.; PEZZUTI, J.; HANAZAKI, N.; PERONI, N.; SILVANO, R. A. M. (Eds.). Ecologia de pescadores da Mata Atlântica e da Amazônia. São Paulo: HUCITEC, 2004. p. $185-220$.

VIANA, J. P.; CASTELLO, L.; DAMASCENO, J. M. B.; AMARAL, E. S. R.; ESTUPIÑÁN, G. M. B.; ARANTES, C.; BATISTA, G. S.; GARCEZ, D. S.; BARBOSA, S. Manejo comunitário do pirarucu Arapaima gigas na Reserva de Desenvolvimento Sustentável Mamirauá - Amazonas, Brasil. In: PRATES, A. P.; BLANC, D. (Orgs.). Áreas aquáticas protegidas como instrumento de gestão pesqueira. Brasília: MMA; IBAMA, 2007. p. 239-261.

WAICHMAN, A. V.; PINHEIRO, M.; MARCON, J. L. Water quality monitoring during the transport of Amazonian ornamental fish. In: CHAO, N. L.; PETRY, P.; PRANG, G.; SONNESCHIEN, L.; TLUSTY, M. (Eds.). Conservation and management of ornamental fish resources of the Rio Negro Basin, Amazonia, Brazil - Project Piaba. Manaus: Editora da Universidade do Amazonas, 2001. p. 279-299.

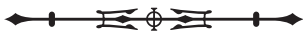

